\title{
The A53T $\alpha$-Synuclein Mutation Increases Iron-Dependent Aggregation and Toxicity
}

\author{
Natalie Ostrerova-Golts, ${ }^{1}$ Leonard Petrucelli, ${ }^{1}$ John Hardy, ${ }^{3}$ John M. Lee, ${ }^{1,2}$ Matthew Farer, ${ }^{3}$ and \\ Benjamin Wolozin ${ }^{1}$
}

Departments of ${ }^{1}$ Pharmacology and 2 Pathology, Loyola University Medical Center, Maywood, Illinois 60153, and

${ }^{3}$ Department of Pharmacology, Mayo Clinic, Jacksonville, Florida 32224

\begin{abstract}
Parkinson's disease (PD) is the most common motor disorder affecting the elderly. PD is characterized by the formation of Lewy bodies and death of dopaminergic neurons. The mechanisms underlying PD are unknown, but the discoveries that mutations in $\alpha$-synuclein can cause familial PD and that $\alpha$-synuclein accumulates in Lewy bodies suggest that $\alpha$-synuclein participates in the pathophysiology of PD. Using human BE-M17 neuroblastoma cells overexpressing wild-type, A53T, or A30P $\alpha$-synuclein, we now show that iron and free radical generators, such as dopamine or hydrogen peroxide, stimulate the production of intracellular aggregates that contain $\alpha$-synuclein and ubiquitin. The aggregates can be identified by immunocytochemistry, electron microscopy, or the histochemical stain thioflavine S. The amount
\end{abstract}

of aggregation occurring in the cells is dependent on the amount of $\alpha$-synuclein expressed and the type of $\alpha$-synuclein expressed, with the amount of $\alpha$-synuclein aggregation following a rank order of A53T > A30P > wild-type > untransfected. In addition to stimulating aggregate formation, $\alpha$-synuclein also appears to induce toxicity. BE-M17 neuroblastoma cells overexpressing $\alpha$-synuclein show up to a fourfold increase in vulnerability to toxicity induced by iron. The vulnerability follows the same rank order as for aggregation. These data raise the possibility that $\alpha$-synuclein acts in concert with iron and dopamine to induce formation of Lewy body pathology in PD and cell death in PD.

Key words: Parkinson's disease; Lewy body; oxidation; neurodegeneration; ubiquitin; dopamine
Parkinson's disease (PD) is a common neurodegenerative disorder. The four primary diagnostic signs of the illness are resting tremor, bradykinesia, muscular rigidity, and postural instability. These signs of motor deficiency result from the loss of dopaminergic neurons in the nigrostriatal system (Gibb and Lees, 1988). The neuropathological hallmark of PD is the Lewy body. Lewy bodies are intracytoplasmic inclusions that occur in degenerating neurons, which are composed of a dense core of filamentous and granular material surrounded by radially oriented filaments that have a diameter of 10-20 nm (Goedert et al., 1999). In general, the causes of PD are not known, and there has been vigorous debate over the relative roles of genetics and environmental factors (Tanner et al., 1999). The only defined causes of the disease are A53T and A30P mutations in the $\alpha$-synuclein gene (Polymeropoulos et al., 1997; Goedert et al., 1999; Papadimitriou et al., 1999), but there has been much circumstantial evidence implicating oxidative stress in the etiology of the disease (Jenner and Olanow, 1998). Immunohistochemical studies indicate that Lewy bodies stain strongly for $\alpha$-synuclein and ubiquitin (Spillantini et al., 1997; Jenner and Olanow, 1998; Spillantini et al., 1998; Markopoulou et al., 1999). The mechanisms by which mutations in $\alpha$-synuclein lead to PD are unknown. One study suggest that the mutations might reduce $\alpha$-synuclein expression (Markopoulou et al., 1999). However, most in vitro experiments using recombinant protein suggest that the mutations lead to increases in $\alpha$-synuclein aggregation because of an increase in the rate of aggregation of mutant A53T and A30P proteins compared with wild-type $\alpha$-synuclein (Conway et al., 1998; Hashimoto et al., 1998; Giasson et al., 1999). These findings suggest that increased rate of $\alpha$-synuclein aggregation might contribute to the mechanisms of neurodegeneration in PD.

Recently, oxidative stress produced by iron and hydrogen peroxide has been shown to induce amyloid-like aggregate formation

Received Feb. 22, 2000; revised June 5, 2000; accepted June 5, 2000.

This work was supported by a grant from the Retirement Research Foundation (to B.W.) and the National Parkinson Foundation (to B.W.).

Correspondence should be addressed to Dr. Benjamin Wolozin, Department of Pharmacology, Loyola University Medical Center, Building 102, Room 4644, 2160 South 1st Avenue, Maywood, IL 60154. E-mail: bwolozi@luc.edu.

Copyright (C) 2000 Society for Neuroscience $0270-6474 / 00 / 206048-07 \$ 15.00 / 0$ of $\alpha$-synuclein in vitro (Hashimoto et al., 1999; Paik et al., 1999). Oxidative stress is thought to contribute to PD because dopamine, which is a strong free radical generator, is the principle neurotransmitter in the substantia nigra (Chiueh et al., 1993; Jenner and Olanow, 1998). In addition, iron, which also stimulates free radical production, accumulates in the substantia nigra with age (Jenner and Olanow, 1998). Thus, the oxidative conditions present in the substantia nigra could promote $\alpha$-synuclein aggregation. Whether such oxidative conditions actually promote $\alpha$-synuclein aggregation in living neurons, however, is unknown.

\section{MATERIALS AND METHODS}

Materials. $\alpha$-Synuclein (wild-type, A53T, and A30P) was cloned into the NotI site of pcDNA3. The sequence of each construct was confirmed by DNA sequencing. For production of recombinant protein, $\alpha$-synuclein was inserted into the NcoI/NotI site of the Pro-Ex His-6 vector (Life Technologies, Gaithersburg, MD). To generate recombinant $\alpha$-synuclein, BPer (Pierce, Rockford, IL) reagent was used to solubilize the recombinant $\alpha$-synuclein from the isopropylthio- $\beta$-D-galactoside-induced bacterial lysates, which were then passed over a nickel-agarose affinity column, washed, and eluted with imidazole according to the directions of the manufacturer (Life Technologies). After purification, the His-6 tag was cleaved with tobacco etch virus protease and removed by passing through a nickel-agarose column. Antibodies used include the following: polyclonal anti- $\alpha$-synuclein (SC1; 1:2000 for immunoblotting and 1:500 for immunocytochemistry against human $\alpha$-synuclein; residues 116-131; sequence, MPVDPDNEAYEMPSEE), monoclonal anti- $\alpha$-synuclein-1 (1:1000; Transduction Laboratories, Lexington, KY), and polyclonal rabbit antiubiquitin (1:1000 for immunoblotting and 1:500 for immunocytochemistry; Dako, High Wycombe, UK).

Cell culture. Cells were grown in OPTIMEM (Life Technologies) supplemented with $10 \%$ FBS, nonessential amino acids, sodium pyruvate, and $500 \mu \mathrm{g} / \mathrm{ml} \mathrm{G} 418$, as needed. G418 was used for selection.

Immunoblotting. Cells were harvested with SDS lysis solution [2\% SDS, $10 \mathrm{~mm}$ Tris, pH 7.4, $2 \mathrm{~mm} \beta$-glycerol phosphate, and $1 \mu \mathrm{M} 4-(2-$ aminoethyl)benzenesulfonyl fluoride hydrochloride]. The amount of protein was determined using the BCA assay (Pierce); 5-30 $\mu \mathrm{g} /$ lane was run on $14 \%$ SDS polyacrylamide gels and transferred to nitrocellulose (200 $\mathrm{mA}, 12 \mathrm{hr}$ ). The nitrocellulose was then incubated $1 \mathrm{hr}$ in $5 \%$ milk-PBS, washed, incubated overnight in $1^{\circ}$ antibody, washed, then incubated $3 \mathrm{hr}$ in peroxidase-coupled $2^{\circ}$ antibody, and developed with chemiluminescent reagent (NEN, Boston, MA).

Cell fractionation. For cell fractionation, the cells were harvested in buffer containing $20 \mathrm{~mm}$ Tris, $\mathrm{pH}$ 7.4, $2 \mathrm{~mm}$ EDTA, $0.25 \mathrm{~m}$ sucrose, and 20 
$\mu \mathrm{g} / \mathrm{ml}$ protease inhibitor cocktail (Sigma, St. Louis, MO). The cell lysate was sonicated and centrifuged at $100,000 \times g$ at $4^{\circ} \mathrm{C}$ for $1 \mathrm{hr}$.

MTT and lactate dehydrogenase toxicity assay. Cells were plated in 96 well dishes at 5000 cells per well in $100 \mu \mathrm{l}$ of growth medium. For the MTT assay, viability after $48 \mathrm{hr}$ of pharmacological treatment was analyzed by adding $0.5 \mathrm{mg} / \mathrm{ml} \mathrm{MTT}$ and incubating at $37^{\circ} \mathrm{C}$ for $3 \mathrm{hr}$. Lysis buffer $(100$ $\mu \mathrm{l}$ of $20 \%$ SDS in $50 \% N, N$-dimethylformamide) was then added, and the plates are read at $540 \mathrm{~nm}$ after $24 \mathrm{hr}$. For the lactate dehydrogenase (LDH) assay, viability after $24 \mathrm{hr}$ of pharmacological treatment was analyzed using MTS reagent and the Cytox 96 kit (Promega, Madison, WI) according to the directions of the manufacturer.

Thioflavine S histochemistry. Cells were fixed $30 \mathrm{~min}$ in $4 \%$ paraformaldehyde. After two PBS washes, the cells were incubated with $0.5 \%$ thioflavine $\mathrm{S}$ for $8 \mathrm{~min}$, washed three times in $80 \%$ ethanol, washed once in $\mathrm{H}_{2} \mathrm{O}$, and then mounted.

Electron microscopy. Cells were detached by scraping, spun down, fixed in $2 \%$ glutaraldehyde for $2 \mathrm{hr}$ at $4^{\circ} \mathrm{C}$, and then post-fixed in $1 \%$ osmium tetroxide for $1 \mathrm{hr}$ at $4^{\circ} \mathrm{C}$. The samples were dehydrated, embedded in epoxy resin (Electron Microscopy Sciences, Fort Washington, PA), and cut into $70 \mathrm{~nm}$ sections for microscopy. The sections were then post-stained with $5 \%$ uranyl acetate and Reynolds lead citrate. Samples were viewed with a Hitachi H-600 transmission electron microscope at $75 \mathrm{kV}$.

Iron staining. Cells were fixed $30 \mathrm{~min}$ in $4 \%$ paraformaldehyde, followed by two PBS washes, and stained using the Accustain Iron Stain according to the directions of the manufacturer (Sigma).

Immunohistochemistry. For light microscopy, cells were fixed with $4 \%$ paraformaldehyde, washed, permeabilized by incubation for $30 \mathrm{~min}$ with $0.2 \%$ Triton X-100, blocked with $5 \%$ dry milk-1\% goat serum-PBS, washed, and then incubated overnight in $1^{\circ}$ antibody (1:500). Development was with an $\mathrm{ABC}$ kit and $3^{\prime}, 3^{\prime}$-diaminobenzidine as per the directions of the manufacturer (Vector Laboratories, Burlingame, CA).

\section{RESULTS}

Iron and free radicals stimulate $\alpha$-synuclein aggregation

To test whether A53T and A30P mutations in $\alpha$-synuclein increase the tendency of $\alpha$-synuclein to aggregate in neurons, we examined $\alpha$-synuclein aggregation in human BE-M17 neuroblastoma cells stably transfected with wild-type, A53T, or A30P $\alpha$-synuclein (Fig. $1 A)$. Each cell line was treated for $48 \mathrm{hr}$ with freshly prepared $\mathrm{FeCl}_{2}$ (1 or $10 \mathrm{~mm}$ ) and then harvested, homogenized, and fractionated into membrane and cytoplasmic components. The membrane $(5 \mu \mathrm{g} /$ lane $)$ and cytoplasmic $(20 \mu \mathrm{g} /$ lane $)$ components were immunoblotted with monoclonal anti- $\alpha$-synuclein antibody. Aggregates of $\alpha$-synuclein were evident in the membrane fraction but not in the cytoplasmic fraction (Fig. 1, membrane fraction shown). Treatment of the A53T-expressing cell line with $\mathrm{FeCl}_{2}$ induced dose-dependent formation of heterogeneous high molecular weight $\alpha$-synuclein aggregates that migrated in the stacking gel (Fig. $1 B$, solid bracket). A large amount of anti- $\alpha$-synuclein immunoreactivity was also apparent in the upper portions of the separating gel, in the range of $45-200 \mathrm{kDa}$ (Fig. $1 B$, lane 2, dotted bracket). Because these bands are significantly larger than monomeric $\alpha$-synuclein, which has a mass of $19 \mathrm{kDa}$, these bands might also represent $\alpha$-synuclein polymers and aggregates. For instance, the bands at 38 and $57 \mathrm{kDa}$ have sizes consistent with dimers and trimers of $\alpha$-synuclein. Immunoblots done with a different antibody, a polyclonal anti- $\alpha$-synuclein antibody, also showed aggregate production under the same conditions (data not shown). Treatment of the other cell lines (untransfected, wild-type, and A30P) did not induce $\alpha$-synuclein aggregates within the $48 \mathrm{hr}$ time frame examined (data not shown).

To determine whether increasing the duration of exposure to iron produced aggregation of $\alpha$-synuclein at lower doses of iron, we exposed BE-M17 cells overexpressing A53T or wild-type $\alpha$-synuclein to $\mathrm{FeCl}_{2}$ for $4 \mathrm{~d}$. Under these conditions, doses as low as $0.3 \mu \mathrm{M} \mathrm{FeCl} l_{2}$ produced detectable aggregation of $\alpha$-synuclein in cells expressing A53T $\alpha$-synuclein (Fig. 1C, left panel). Interestingly, these longer conditions also induced aggregation of wild-type $\alpha$-synuclein (Fig. 1C, middle panel). In contrast, no aggregation of actin was observed, which suggests that aggregation is selective for $\alpha$-synuclein (Fig. 1C, right panel). We also examined whether $\mathrm{Bcl}-2$-associated death protein (BAD) aggregated, because BAD is a pro-apoptotic protein that binds to $\alpha$-synuclein (Osterova et al., 1999). However, no aggregated BAD reactivity was apparent (data not shown).

To understand how the pattern of $\alpha$-synuclein aggregation in the
A.
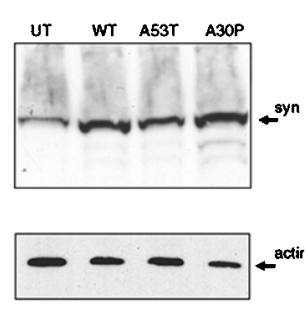

B.

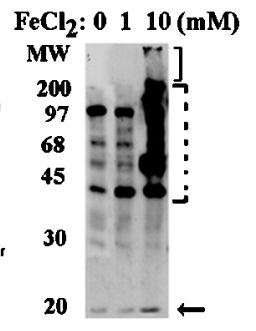

D.

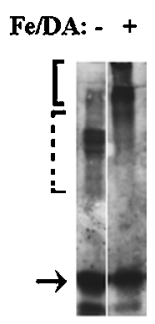

C.

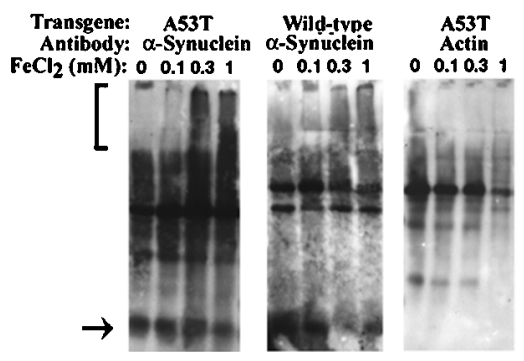

Figure 1. Iron stimulates $\alpha$-synuclein aggregation. $A$, Immunoblot of $\alpha$-synuclein in cell lines overexpressing wild-type $(W T), \mathrm{A} 53 \mathrm{~T}$, and A30P $\alpha$-synuclein using the monoclonal anti- $\alpha$-synuclein antibody (top). The same immunoblot was then stripped and reprobed with antibody to actin. $U T$, Untransfected. $B$, Aggregation of $\alpha$-synuclein in BE-M17 cells expressing A53T $\alpha$-synuclein after treatment with 1 or $10 \mathrm{mM} \mathrm{FeCl2}$ for $48 \mathrm{hr}$ (in each panel, the solid bracket shows putative aggregates in the stacking gel, and the dotted bracket shows putative aggregates in the separating gel). $C$, Longer exposure (4 d) enabled lower doses of $\mathrm{FeCl}_{2}$ to induce aggregation of $\alpha$-synuclein BE-M17 cells expressing A53T $\alpha$-synuclein (left) or wildtype $\alpha$-synuclein (middle). Under these conditions, little or no aggregation of actin was observed (right). D, In vitro analysis of $\alpha$-synuclein aggregation. Immunoblotting of $\alpha$-synuclein in brain membrane fractions under basal conditions (lane 1) or after treatment with $10 \mathrm{mM} \mathrm{FeCl}_{2}$ and $500 \mu \mathrm{M}$ dopamine $(D A)$ for $24 \mathrm{hr}$ (lane 2) shows the induction of high molecular weight aggregates similar to that seen in the BE-M17 cells.

BE-M17 cells compares with that occurring in human brain, we investigated the response of $\alpha$-synuclein in human cortical brain homogenates (from a neurologically normal donor) to iron exposure in vitro. The pattern of $\alpha$-synuclein aggregation in the membrane fraction of the cortical brain homogenate after treatment for $24 \mathrm{hr}$ with $500 \mu \mathrm{M}$ dopamine, $10 \mathrm{mM} \mathrm{FeCl}_{2}$, and protease inhibitors (dopamine was added as an oxidant, as described below) was similar to that seen in the BE-M17 cells. This suggests that $\alpha$-synuclein in BE-M17 cells and in human brain exhibit similar aggregation patterns in response to iron, and both share a strong tendency to aggregate.

In the course of our investigations, we noted that higher molecular weight $\alpha$-synuclein immunoreactivity occasionally appeared in separating gels of immunoblots of $\alpha$-synuclein cell lysates from cells grown under basal conditions (Fig. $1 C$ ). However, aggregates that migrated in the stacking gel only occurred after treatment with iron and were never observed in any of the cell lines under basal conditions. This supports previous work done with recombinant $\alpha$-synuclein in vitro indicating that the mutant forms of $\alpha$-synuclein have a strong tendency to oligomerize (Conway et al., 2000). However, migration of aggregates in the stacking gel might be a stricter test of aggregate formation than migration in the separating gel.

Iron might promote protein aggregation by increasing free radical formation through the Fenton reaction (Wolozin and Behl, 2000). If so, then adding free radical generators, such as hydrogen peroxide or dopamine, along with the iron might increase the amount of $\alpha$-synuclein aggregation. To test whether oxidation enhanced iron-induced aggregation of $\alpha$-synuclein, we treated BEM17 cells overexpressing A30P or wild-type $\alpha$-synuclein for $48 \mathrm{hr}$ with $10 \mathrm{mM} \mathrm{FeCl}_{2}$ plus varying concentrations of dopamine (Fig. $2 A$, A30P overexpressing cells shown). We used cells expressing A30P or wild-type $\alpha$-synuclein over $48 \mathrm{hr}$ because they do not form 

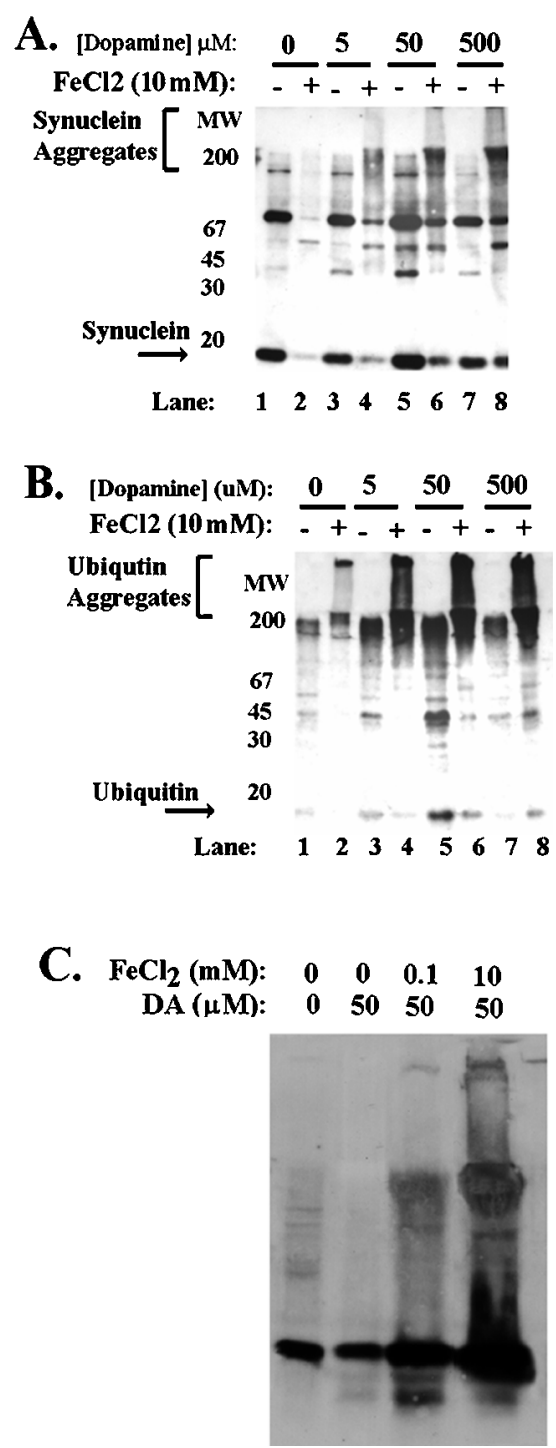

Figure 2. Free radicals potentiate induction of $\alpha$-synuclein aggregation by iron. $A, B$, Aggregation of $\alpha$-synuclein in BE-M17 cells expressing A30P $\alpha$-synuclein after treatment with $0,5,50$, and $500 \mu \mathrm{M}$ dopamine plus or minus $10 \mathrm{mM} \mathrm{FeCl}_{2}$ for $48 \mathrm{hr}$. The immunoblot was first probed with monoclonal anti-synuclein antibody $(A)$ and then reprobed with antiubiquitin antibody $(B)$. $C$, Immunoblots of lysates from primary cortical neurons after treatment with $0,0.1$, or $10 \mathrm{mM} \mathrm{FeCl}_{2}$ and $50 \mu \mathrm{M}$ dopamine $(D A)$ for $60 \mathrm{hr}$.

aggregates under these conditions, unlike cells overexpressing A53T $\alpha$-synuclein. As expected, BE-M17 cells overexpressing A30P or wild-type $\alpha$-synuclein treated with $10 \mathrm{mM} \mathrm{FeCl}_{2}$ alone did not induce any aggregation (Fig. $2 A$, lane 2). Similarly, treatment with 5,50 , or $500 \mu \mathrm{M}$ dopamine alone did not induce formation of large $\alpha$-synuclein aggregates that migrate in the stacking gel (Fig. $2 A$, lanes $3,5,7)$. However, combining $10 \mathrm{~mm} \mathrm{FeCl}_{2}$ with 50 or 500 $\mu \mathrm{M}$ dopamine induced formation of large $\alpha$-synuclein aggregates (Fig. $2 A$, lanes 6,8 ). These data show that the combination of oxidants and iron can exert additive effects on $\alpha$-synuclein aggregation.

Two separate experiments indicated that the aggregation observed was a general property of $\alpha$-synuclein rather than an artifact resulting from use of clonal cell lines. BE-M17 cells that were transiently transfected with A53T $\alpha$-synuclein cDNA and then

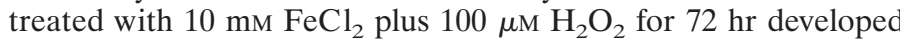
aggregates similar to those seen in the BE-M17 cell lines stably overexpressing $\alpha$-synuclein (data not shown). In addition, primary rat cortical neurons also showed a strong tendency to develop aggregates, requiring only $60 \mathrm{hr}$ of treatment with $0.1 \mathrm{~mm} \mathrm{FeCl}_{2}$ and $50 \mu \mathrm{M}$ dopamine to induce formation of aggregates (Fig. $2 C$ ). Thus, the aggregation was a result of a biophysical property of $\alpha$-synuclein rather than being an artifact specific to particular clonal cell lines.

\section{A53T and A30P $\alpha$-synuclein aggregates contain ubiquitin}

In PD, Lewy bodies have also been shown to contain large amounts of ubiquitin (Gibb and Lees, 1988; Dickson et al., 1999). The presence of ubiquitin in Lewy bodies prompted us to examine whether aggregation of ubiquitin also occurred along with $\alpha$-synuclein aggregation. We took lysates (membrane fractions) from the BE-M17 cells expressing A30P $\alpha$-synuclein that had been treated with $\mathrm{FeCl}_{2}$ and dopamine (Fig. $2 A$ ) and immunoblotted them with anti-ubiquitin antibody (Fig. $2 B$ ). The ubiquitin aggregates that accumulated under these conditions stained strongly for ubiquitin (Fig. 2A,B). Aggregates that accumulated in cells expressing A53T $\alpha$-synuclein or wild-type $\alpha$-synuclein after being treated with $\mathrm{FeCl}_{2}$ alone, $\mathrm{FeCl}_{2}$ plus hydrogen peroxide, or $\mathrm{FeCl}_{2}$ plus dopamine also contained ubiquitin (data not shown). In many cases, ubiquitin appeared to be a more sensitive indicator of aggregation on the immunoblots than $\alpha$-synuclein (Fig. 2B). The amount of aggregated ubiquitin generally paralleled the amount of $\alpha$-synuclein (Fig. $2 A, B$ ). The presence of ubiquitin in aggregates did not appear to result from increased ubiquitin expression because immunoblots of total lysates showed that the total amount of ubiquitin and actin did not different significantly between cell lines overexpressing $\alpha$-synuclein and control cells. These data suggest that aggregates of $\alpha$-synuclein that form in neurons in response to iron treatment are ubiquinated.

\section{$\alpha$-Synuclein aggregates form visible inclusions evident by thioflavine $\mathrm{S}$ histochemistry and electron microscopy}

Next, we used thioflavine $\mathrm{S}$ histochemistry and electron microscopy to examine the aggregates that formed in response to treatment with iron and hydrogen peroxide. We treated cells from each line (BE-M17: untransfected, wild-type, A30P, and A53T $\alpha$-synuclein) with $10 \mathrm{mM} \mathrm{FeCl}_{2}$ or $10 \mathrm{~mm} \mathrm{FeCl}$ plus $100 \mu \mathrm{M} \mathrm{H}_{2} \mathrm{O}_{2}$ for $72 \mathrm{hr}$ to induce formation of $\alpha$-synuclein-positive inclusions. The aggregates that formed were observed to bind thioflavine $\mathrm{S}$, which indicates the presence of $\beta$-pleated sheet structures (Fig. 3). The size and number of thioflavine $S$-positive aggregates paralleled the results seen by immunoblotting. The wild-type, A30P, and A53T $\alpha$-synuclein cell lines each showed significant accumulations of protein aggregates after treatment for $72 \mathrm{hr}$ with $10 \mathrm{mM} \mathrm{FeCl}_{2}$ plus $100 \mu \mathrm{M} \mathrm{H} \mathrm{H}_{2}$ (Fig. $3 A, B$ ). In contrast, the untransfected line showed no accumulation of thioflavine S-positive aggregates (Fig. $3 C$ ). When only $10 \mathrm{~mm} \mathrm{FeCl}_{2}$ was used to treat the cells, shown thioflavine S-positive inclusions were observed only in A53T $\alpha$-synuclein-expressing cells (Fig. 3D-F).

Next, we used electron microscopy to examine the aggregates. Cells expressing A53T $\alpha$-synuclein or empty vector were treated with $10 \mathrm{mM} \mathrm{FeCl}_{2}$ plus $100 \mu \mathrm{M} \mathrm{H}_{2} \mathrm{O}_{2}$ for $72 \mathrm{hr}$ and then prepared for electron microscopy. Cytoplasmic inclusions were apparent in the A53T-expressing cells but not in the vector-transfected cells (Fig. $3 G, H)$. The inclusions contained mixtures of fibrillar and amorphous material (Fig. 3G). The fibrils had an approximate diameter of $10 \mathrm{~nm}$ and a length of up to $10 \mu \mathrm{m}$. The presence of both fibrillar and amorphous material in the aggregates has been observed in aggregates present in transgenic animals overexpressing $\alpha$-synuclein (Feany and Bender, 2000; Masliah et al., 2000).

\section{$\alpha$-Synuclein aggregates form visible inclusions evident by immunohistochemistry}

We also examined the inclusion formation by immunocytochemistry. Cells expressing A53T $\alpha$-synuclein were treated with $10 \mathrm{~mm}$ $\mathrm{FeCl}_{2}$ plus $100 \mu \mathrm{M} \mathrm{H}_{2} \mathrm{O}_{2}$ for $72 \mathrm{hr}$, fixed, and then examined with antibodies to ubiquitin and $\alpha$-synuclein using peroxidase immunohistochemistry. We used peroxidase staining because fluorescent 

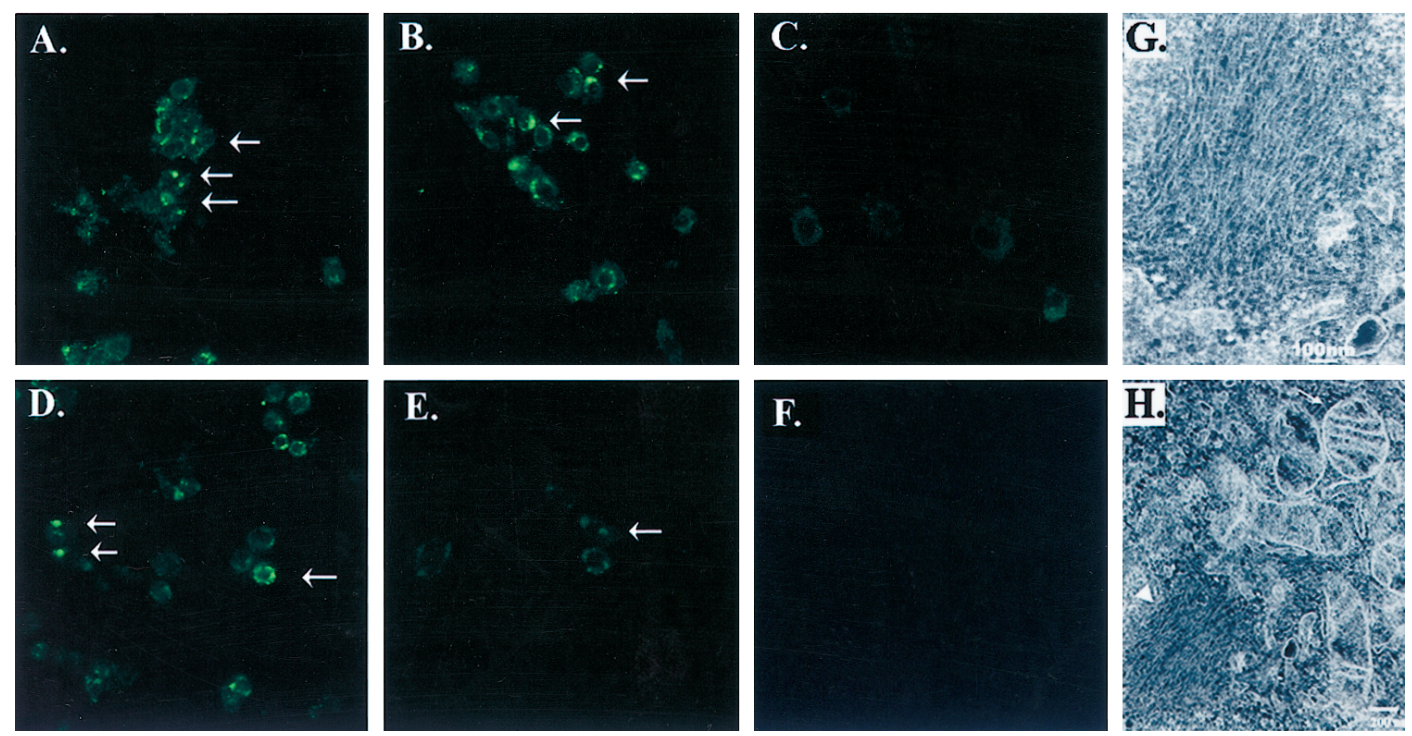

Figure 3. Identifcation of $\alpha$-synuclein aggregates by thioflavine $\mathrm{S}$ staining and by electron microscopy. $A-C$, Treatment of cells expressing A53T $\alpha$-synuclein $(A)$, wild-type $\alpha$-synuclein $(B)$, or untransfected cells $(C)$ with $10 \mathrm{~mm} \mathrm{FeCl} \mathrm{F}_{2}$ and $100 \mu \mathrm{M} \mathrm{H}_{2} \mathrm{O}_{2}$ for 72 hr. $D-F$, Treatment of cells expressing A53T $\alpha$-synuclein $(D)$, wild-type $\alpha$-synuclein $(E)$, or untransfected cells $(F)$ with $10 \mathrm{~mm} \mathrm{FeCl}_{2}$ for $72 \mathrm{hr}$. $G, H$, Inclusions are evident by electron microscopy. BE-M17 cells stably transfected with A53T $\alpha$-synuclein were treated with $10 \mathrm{mM} \mathrm{FeCl}_{2}$ and $100 \mu \mathrm{M} \mathrm{H}_{2} \mathrm{O}_{2}$ for 72 hr and then examined by electron microscopy. The aggregates that formed under these conditions were long fibrils with a diameter of $\sim 10 \mathrm{~nm}(G$, magnification of $35,000 \times)$. Although treatment with $10 \mathrm{mM} \mathrm{FeCl}_{2}$ and $100 \mu \mathrm{M} \mathrm{H} \mathrm{H}_{2} \mathrm{O}_{2}$ was toxic to many cells, some cells containing aggregates had both fibrillar deposits (triangle) and organelles that were intact (arrow), suggesting that aggregation can occur in living cells ( $H$, magnification of $20,000 \times$ ). Arrows point to thioflavine S-positive aggregates.

chromagens, such as FITC or rhodamine, exhibited strong nonspecific binding to the cells because of the treatment with iron. Immunohistochemistry with both the anti- $\alpha$-synuclein and antiubiquitin antibodies showed uniform staining throughout the cytoplasm of the cells under basal conditions (Fig. $4 A, B$ ). After treatment with $10 \mathrm{mM} \mathrm{FeCl}_{2}$ plus $100 \mu \mathrm{M} \mathrm{H}_{2} \mathrm{O}_{2}$ for $72 \mathrm{hr}$, the staining became less uniform. Cells stained with anti- $\alpha$-synuclein antibody often displayed several large darkly stained reactive foci and multiple small punctate foci in each cell (Fig. 4C). Staining with ubiquitin was also present but showed foci per cell (Fig. 4D). Immunocytochemistry performed with the preimmune rabbit serum instead of primary antibody showed no reactivity under either basal or treated conditions (Fig. $4 E, F$ ).

\section{$\alpha$-Synuclein aggregation occurs in viable cells}

Treating cells with $\mathrm{FeCl}_{2}$ can be toxic, and it is possible that aggregation of $\alpha$-synuclein occurs after cell death. To determine the relationship between $\alpha$-synuclein aggregation and cell death, we examined aggregate formation and cell viability in the presence of high and low concentrations of $\mathrm{FeCl}_{2}$. As described above (Figs. 3, 4), treatment with $10 \mathrm{~mm} \mathrm{FeCl}_{2}$ plus $100 \mu \mathrm{M} \mathrm{H}_{2} \mathrm{O}_{2}$ for $72 \mathrm{hr}$ induced formation of $\alpha$-synuclein aggregates in most cells; however, these conditions also were observed to kill most of the cells ( $>90 \%$ cell death).

In contrast, A53T-expressing BE-M17 cells treated with $0.3 \mathrm{~mm}$ $\mathrm{FeCl}_{2}$ plus $100 \mu \mathrm{M} \mathrm{H} \mathrm{H}_{2}$ for $96 \mathrm{hr}$ exhibited much less toxicity, yet still formed $\alpha$-synuclein aggregates. Parallel sets of cells were processed for immunocytochemistry with antibodies to $\alpha$-synuclein (SC1) and ubiquitin or were processed to measure viability using the trypan blue exclusion assay. Untreated cells showed little toxicity, with $3.7 \pm 1.0 \%$ being permeable to trypan blue (Fig. 5). The small amount of cell death present might have been caused by the trypsinization-trituration step used to dislodge the cells. Treatment with $0.3 \mathrm{mM} \mathrm{FeCl} \mathrm{F}_{2}$ with or without $100 \mu \mathrm{M} \mathrm{H} \mathrm{H}_{2} \mathrm{O}_{2}$ killed some cells $(12.1 \pm 2.3 \%$ trypan blue-positive $)$, but the large majority of cells $(87.9 \%)$ remained viable (Fig. $5 A)$. Immunocytochemistry with anti- $\alpha$-synuclein antibody showed that $21.0 \pm 3.5 \%$ of the cells had visible aggregates (Fig. $5 B$ ). Immunocytochemistry with antiubiquitin antibody suggested that the aggregates could contain ubiquitin (Fig. 5C) and that the aggregates contained material that had a $\beta$-pleated sheet structure that stained with thioflavine $\mathrm{S}$ (Fig. $5 D$ ). Interestingly, diff use thioflavine $\mathrm{S}$ reactivity was also evident in these cells, suggesting that dispersed "micro-aggregates" of $\alpha$-synuclein might also form under the mild conditions.

Thus, the $\alpha$-synuclein aggregates that formed under mild conditions reacted with the same antibodies and stains as aggregates that formed under harsher conditions. Moreover, the observation that the percentage of cells displaying $\alpha$-synuclein aggregates was greater than the percentage of cells showing evidence of death suggests that many of the cells developing $\alpha$-synuclein aggregates are viable. The observation that aggregation of $\alpha$-synuclein can occur in viable cells also suggests that aggregation of $\alpha$-synuclein precedes cell death.

\section{Overexpression of $\alpha$-synuclein increases free radical-mediated toxicity}

Despite the fact that $\alpha$-synuclein aggregates can form in viable cells, it is possible that aggregation of $\alpha$-synuclein might represent an initial step in the induction of toxicity. Our previous results show that $\alpha$-synuclein is toxic to some cells when transiently overexpressed (Ostrerova et al., 1999). However, $\alpha$-synuclein is not acutely toxic to all cells. $\alpha$-Synuclein is not acutely toxic to BE-M17 cells (data not shown), and $\alpha$-synuclein is tolerated well enough to allow overexpression in transgenic animals (Feany and Bender, 2000; Masliah et al., 2000). Although $\alpha$-synuclein is not acutely toxic to BE-M17 cells under basal conditions, we hypothesized that $\alpha$-synuclein might be toxic under other conditions, such as conditions linked to formation of aggregates.

To determine whether conditions that produce $\alpha$-synuclein aggregation also produce toxicity, we examined the vulnerability of each cell line to iron- and/or hydrogen peroxide-mediated toxicity. Each cell line (untransfected, wild-type, A53T, and A30P $\alpha$-synuclein) was treated with varying doses of $\mathrm{FeCl}_{2}, \mathrm{H}_{2} \mathrm{O}_{2}$, or $\mathrm{FeCl}_{2}$ plus $\mathrm{H}_{2} \mathrm{O}_{2}$, and the amount of toxicity was determined by MTT assay. BE-M17 cells overexpressing all forms of $\alpha$-synuclein showed increased vulnerability to iron-mediated toxicity (Fig. 6A). Overexpression of A53T $\alpha$-synuclein had the greatest effect on toxicity, reducing the $\mathrm{LD}_{50}$ of $\mathrm{FeCl}_{2}$ over $75 \%$ (Fig. $6 \mathrm{~A}$ ). Overexpression of $\mathrm{A} 30 \mathrm{P}$ or wild-type $\alpha$-synuclein constructs reduced the $\mathrm{LD}_{50}$ values by $\sim 50 \%$, although the amount of toxicity seen in 

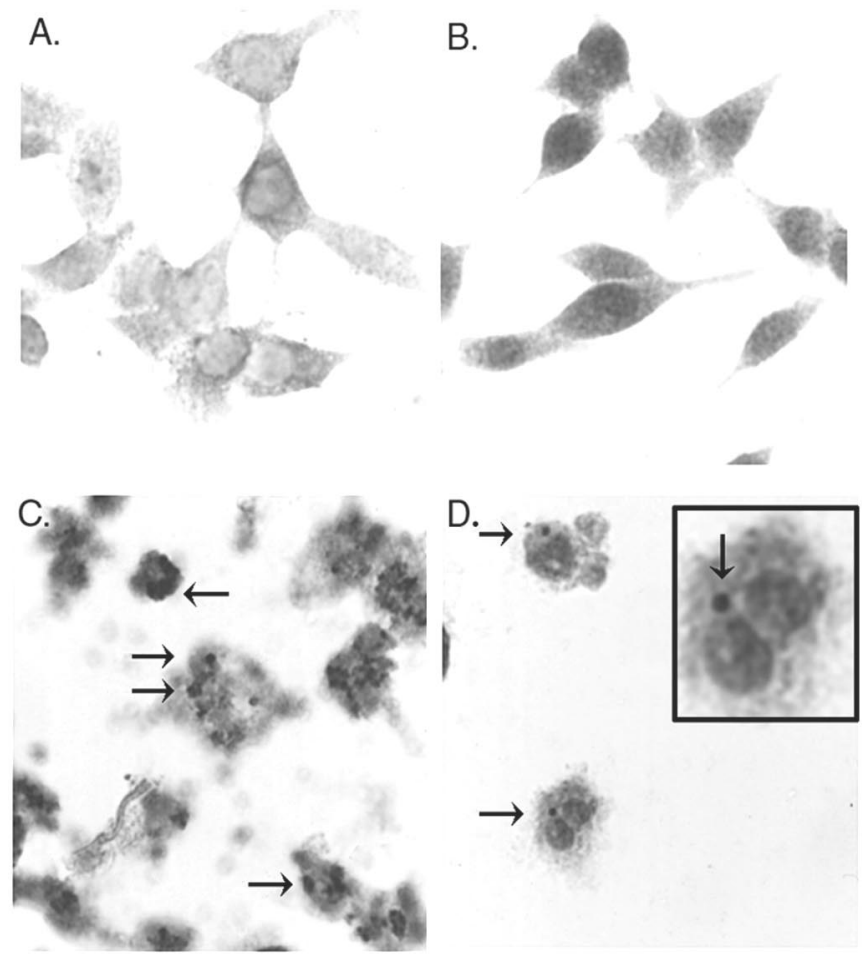

E.

F.

Figure 4. Identification of $\alpha$-synuclein aggregates by immunocytochemistry. $A, B$, Under basal conditions, BE-M17 cells overexpressing A53T $\alpha$-synuclein showed diffuse cytoplasmic staining with antibodies to $\alpha$-synuclein $(A)$ and ubiquitin $(B) . C, D$, Treatment with $10 \mathrm{~mm} \mathrm{FeCl}_{2}$ and $100 \mu \mathrm{M} \mathrm{H} \mathrm{H}_{2} \mathrm{O}_{2}$ for $72 \mathrm{hr}$ induced formation of aggregates, which stained positive using antibodies to $\alpha$-synuclein $(C)$ and ubiquitin $(D)$. Arrows point to some of the labeled inclusions. $E$, In contrast, cells treated with $10 \mathrm{~mm}$ $\mathrm{FeCl}_{2}$ and $100 \mu \mathrm{M} \mathrm{H} \mathrm{H}_{2} \mathrm{O}_{2}$ for $72 \mathrm{hr}$ and stained with preimmune serum showed very little reactivity. $F$, Untreated cells also showed no reactivity with preimmune serum.

A30P-expressing cells in response to low levels of iron was generally greater than toxicity seen with wild-type $\alpha$-synuclein (Fig. 6A). To confirm that overexpression of $\alpha$-synuclein increased the vulnerability of the neuroblastoma cells to iron, we also examined iron-induced toxicity using an LDH assay (Fig. 6B). The LDH assay confirmed that overexpression of the $\alpha$-synuclein constructs increases iron-induced toxicity (Fig. 6B). MTT assays of cell lines overexpressing $\alpha$-synuclein (wild-type, A53T, or A30P) also revealed increased toxicity after treatment with $\mathrm{FeCl}_{2}$ plus $\mathrm{H}_{2} \mathrm{O}_{2}$ (Fig. $6 C$, dark gray bars). Interestingly, overexpressing $\alpha$-synuclein (wild-type, A53T, or A30P) did not increase the vulnerability to $\mathrm{H}_{2} \mathrm{O}_{2}$ alone and conferred modest protection to the neuroblastoma cells (Fig. $6 \mathrm{C}$ ). These data demonstrate that increased levels of either wild-type or mutant $\alpha$-synuclein can be toxic to neurons grown in cell culture under selective conditions. The data suggest that $\alpha$-synuclein renders the cells particularly vulnerable to ironmediated toxicity. The selective vulnerability to iron could result
A.
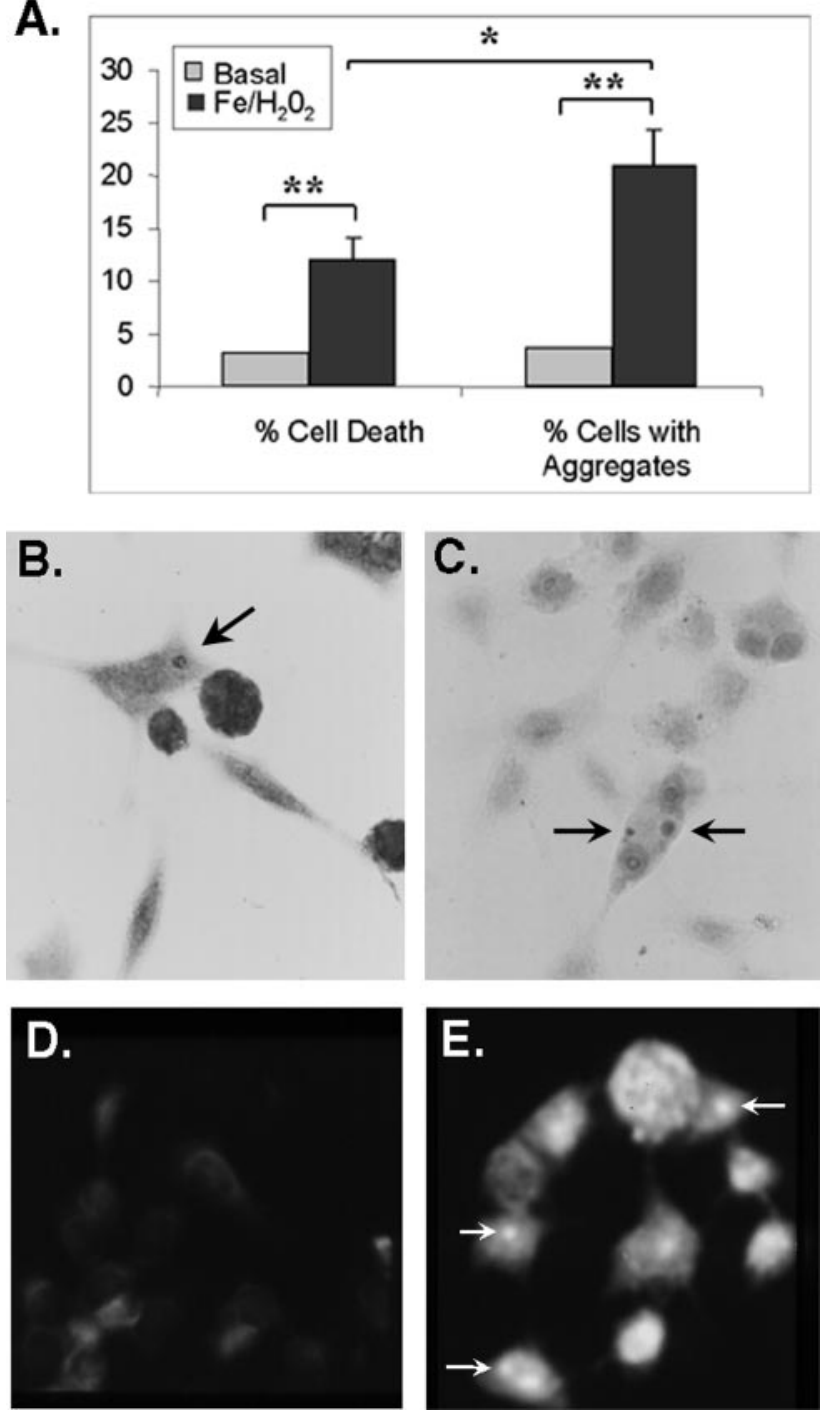

Figure 5. $\quad \alpha$-Synuclein aggregation can occur in viable cells. BE-M17 cells overexpressing A53T $\alpha$-synuclein were treated with $0.3 \mathrm{~mm} \mathrm{FeCl}$ with or without $100 \mu \mathrm{M} \mathrm{H}_{2} \mathrm{O}_{2}$ for $96 \mathrm{hr}$. $A$, Comparison of cell death and aggregate formation in cells expressing A53T $\alpha$-synuclein. Cell viability measurements were based on a trypan blue exclusion assay, and $\alpha$-synuclein aggregates were identified by immunocytochemistry using the anti- $\alpha$-synuclein SC1 antibody. The cell death determinations were based on quantitation of three different samples of treated and untreated cells. Quantitation of aggregates was based on counting the number of cells containing $\alpha$-synuclein aggregates in five microscopy fields chosen at random for treated and untreated cells. ${ }^{*} p<0.05$, ** $p<0.001$. $B, C$, Immunocytochemistry of A53T $\alpha$-synuclein cells treated with $0.3 \mathrm{~mm} \mathrm{FeCl}_{2}$ with or without $100 \mu \mathrm{M} \mathrm{H}_{2} \mathrm{O}_{2}$ for $96 \mathrm{hr}$. $B$ shows aggregates that were positive for $\alpha$-synuclein (SC1 antibody), and $C$ shows aggregates that were positive for ubiquitin (anti-ubiquitin antibody). $D$, A53T $\alpha$-synuclein cells under basal conditions show little staining with thioflavine S. E, Treating A53T $\alpha$-synuclein cells with $0.3 \mathrm{mM} \mathrm{FeCl}_{2}$ for $4 \mathrm{~d}$ induced formation of inclusions that could be stained with thioflavine S. Arrows point to some of the thioflavine S-positive inclusions. In addition, treated cells $(E)$ stained much stronger with thioflavine $\mathrm{S}$ than untreated cells $(D)$.

from a tendency of $\alpha$-synuclein to sequester iron in $\alpha$-synuclein aggregates. To test this, we treated untransfected or A53T $\alpha$-synuclein-expressing BE-M17 cells with $10 \mathrm{mM} \mathrm{FeCl}_{2}$ and 100 $\mu \mathrm{M} \mathrm{H} \mathrm{H}_{2} \mathrm{O}_{2}$ for $48 \mathrm{hr}$, fixed them, and then stained the cells for iron. The cells expressing A53T $\alpha$-synuclein had a much higher iron content than the untransfected cells after treatment (Fig. 6D). Sequestration of iron attributable to $\alpha$-synuclein would increase free radical production via the Fenton reaction, particularly in cells exposed to free radical generators, such as hydrogen peroxide or dopamine. However, in the absence of iron, no Fenton reaction occurs and the $\alpha$-synuclein is innocuous. 

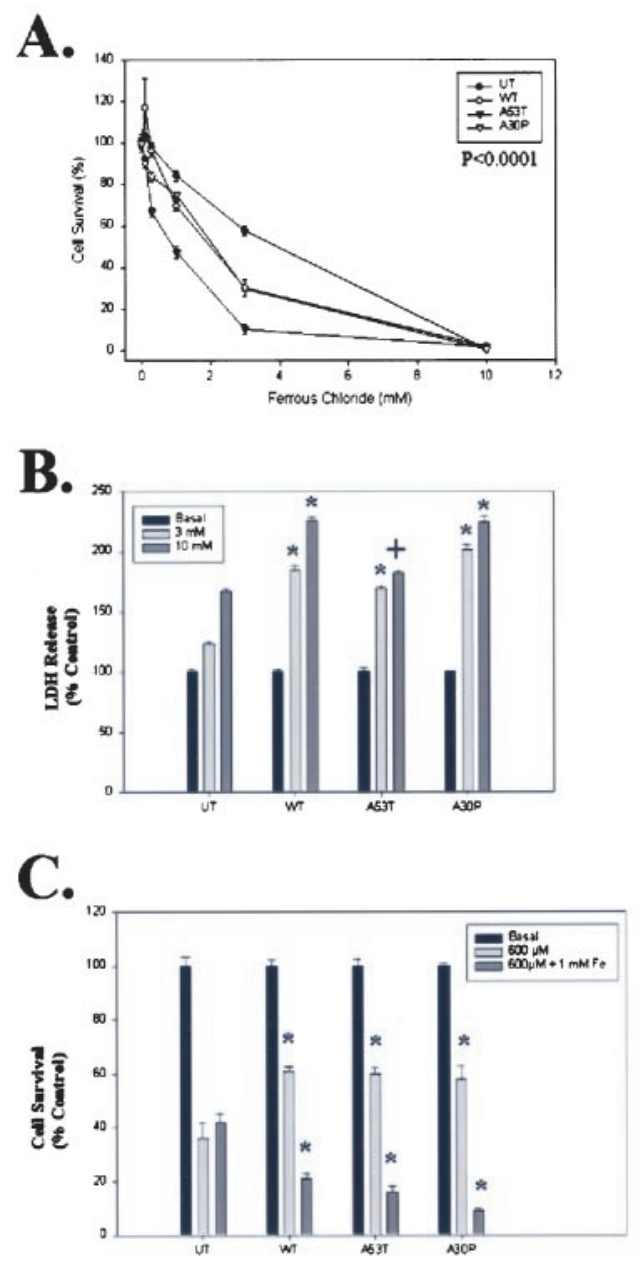

D.

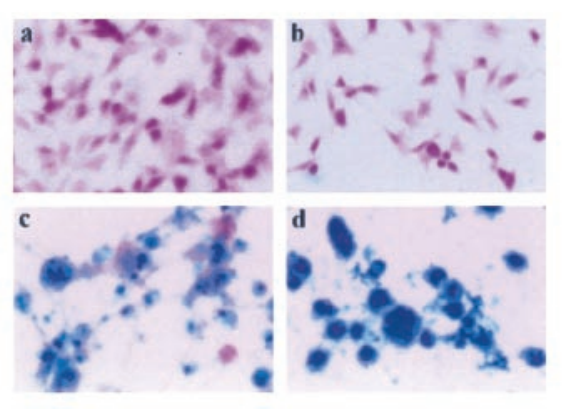

Figure 6. $\alpha$-Synuclein increases iron-dependent toxicity. $A, B$, BE-M17 cells overexpressing wild-type, A53T, or A30P $\alpha$-synuclein were treated with varying doses of $\mathrm{FeCl}_{2}$ for $48 \mathrm{hr}$, and the viability was determined using the MTT assay $(A)$ or the LDH assay $(B)$. $C$, BE-M17 cells overexpressing wild-type, A53T, or A30P $\alpha$-synuclein were treated with varying doses of $\mathrm{H}_{2} \mathrm{O}_{2}$ for $48 \mathrm{hr}$, and the viability was determined using the MTT assay. ${ }^{*} p<0.001,+p<0.01$ by ANOVA analysis. $D$, Iron stain of BE-M17 cells. $a$, Untransfected cells, basal conditions; $b$, A53T $\alpha$-synucleinexpressing cells, basal conditions; $c$, untransfected cells, $\mathrm{FeCl}_{2}-\mathrm{H}_{2} \mathrm{O}_{2}$; $d$, A53T $\alpha$-synuclein-expressing cells, $\mathrm{FeCl}_{2}-\mathrm{H}_{2} \mathrm{O}_{2}$. Under basal conditions, none of the cells showed staining for iron, but after treatment with $10 \mathrm{~mm}$ $\mathrm{FeCl}_{2}$ and $100 \mu \mathrm{M} \mathrm{H}_{2} \mathrm{O}_{2}$ for $48 \mathrm{hr}$, the A53T cells showed much more iron reactivity (blue, iron stain; pink, nuclear-cytoplasmic counterstain).

\section{DISCUSSION}

$\alpha$-Synuclein has gained prominence because mutations in $\alpha$-synuclein cause familial PD in several kindreds and because the protein accumulates in Lewy bodies (Goedert et al., 1999). In vitro studies using recombinant $\alpha$-synuclein show that the protein has a strong tendency to aggregate and that the A53T and A30P mutations increase the rate of aggregation (Conway et al., 1998; Hashi- moto et al., 1998; Giasson et al., 1999). We have now shown that $\alpha$-synuclein also forms aggregates in neurons when cells are exposed to iron or iron plus either hydrogen peroxide or dopamine, which generate free radicals. Moreover, we observe that the A53T $\alpha$-synuclein mutation shows an increased tendency to form aggregates, which is consistent with observations in vitro (Conway et al., 1998, 2000; Hashimoto et al., 1998; Giasson et al., 1999). The aggregates also contain ubiquitin, which is known to be a major component of Lewy bodies. Equally striking is the fact that aggregation is largely restricted to $\alpha$-synuclein, as shown by the observation that actin does not aggregate under these conditions. Cell toxicity per se does not appear to cause aggregation because treatment with dopamine alone, which causes toxicity, does not induce $\alpha$-synuclein aggregation. On the other hand, treating cells with iron does induce $\alpha$-synuclein aggregation, and overexpressing $\alpha$-synuclein sensitizes cells to iron-mediated toxicity. Thus, there appears to be a linkage between toxicity, aggregation, iron, and $\alpha$-synuclein. We propose that aggregation of $\alpha$-synuclein increases cellular iron content, which increases oxidative toxicity. Thus, the interaction between $\alpha$-synuclein and iron might be a critical, and causal, step in the pathophysiology of Parkinson's disease.

Our results implicate iron in the pathophysiology of $\alpha$-synuclein. Exposure of the cells to iron plus other free radical generators, such as dopamine or hydrogen peroxide, was able to induce $\alpha$-synuclein aggregation in all of the cell lines. On the other hand, exposure of cells to dopamine alone did not induce aggregation. These results point to the important role that iron plays in inducing $\alpha$-synuclein aggregation. In the presence of iron, concentrations of dopamine as low as $5 \mu \mathrm{M}$ induce aggregation of all forms of $\alpha$-synuclein (wild-type, A30P, and A53T), which is within the range of dopamine that is thought to be present in the neurons of the substantia nigra.

There is a large amount of circumstantial evidence implicating oxidative factors, especially iron, in both the etiology and pathogenesis of PD and other diseases that exhibit aggregated $\alpha$-synuclein, such as multiple systems atrophy (Koga et al., 1998; Martin et al., 1998; Dickson et al., 1999). Because iron-induced $\alpha$-synuclein aggregation is dose-dependent, the accumulation of iron in the substantia nigra that occurs during aging or Lewy body disease might increase the rate of aggregation of $\alpha$-synuclein. In fact, iron has been shown recently to be present in Lewy bodies in the substantia nigra (Castellani et al., 2000). The presence of dopamine combined with the accumulation of iron substantia nigra of elderly subjects might therefore promote the aggregation of $\alpha$-synuclein and formation of Lewy bodies.

Lewy bodies also contain a large amount of ubiquitin (Leroy et al., 1998). Our studies revealed that the aggregates formed in the BE-M17 cells in response to the conditions that produced $\alpha$-synuclein aggregation also contain ubiquitin. The amount of ubiquitin protein that accumulated in the aggregates appeared to be proportional to the amount of $\alpha$-synuclein aggregation. This suggests that the process of $\alpha$-synuclein aggregation is coupled to ubiquitination. Many studies have observed that both $\alpha$-synuclein and ubiquitin are abundant in Lewy bodies and other types of $\alpha$-synuclein pathology (Spillantini et al., 1997, 1998; Masliah et al., 2000). Whether ubiquitin or $\alpha$-synuclein is more abundant in iron-induced aggregates was not determined in our experiments because the amount of antigen detected varied depending on the method and antibody used. Anti-ubiquitin antibodies were more sensitive than anti- $\alpha$-synuclein antibodies by immunoblot, whereas the converse was true by immunocytochemistry. Similarly, antibodies to $\alpha$-synuclein also displayed differential sensitivities, depending on the epitope. The monoclonal antibody directed against the $\mathrm{N}$ terminus was better than the SC1 antibody in detecting aggregates by immunoblotting, whereas the $\mathrm{SC} 1$ antibody was better than the monoclonal antibody at detecting aggregates by immunocytochemistry. The differences in sensitivity might depend on epitope availability and have been noted by other investigators (Serpell et al., 2000). The most parsimonious conclusion from this data is that $\alpha$-synuclein and ubiquitin are both abundant in the aggregates. 
One of the important questions regarding $\alpha$-synuclein aggregation and Lewy body formation is whether these processes harm the cell. Lewy bodies could be inert tombstone markers that occur in response to free radical damage, or they might be toxic agents that harm the cell. Examples of both situations exist in the literature. Aggregated $\mathrm{A} \beta$ is toxic to neurons, whereas the lipofuscin appears to be innocuous to cells (Behl et al., 1994). The Huntingtin protein presents an intermediate situation in which the toxicity associated with Huntingtin appears to precede aggregation, and aggregation of Huntingtin might even be protective (Saudou et al., 1998). Our previous studies showed that transient overexpression of $\alpha$-synuclein is toxic to a variety of cells, including two neuronal cell lines, SK-NSH and PC12 (Ostrerova et al., 1999). Consistent with this observation, Masliah et al. (2000) have shown recently that mice overexpressing $\alpha$-synuclein show an age-related loss of dopaminergic terminals and motor impairment, which could be indicative of toxicity. In the present study, we observed that $\alpha$-synuclein increases iron-mediated toxicity and that in some assays the A53T $\alpha$-synuclein construct was more toxic than the wild-type or A30P $\alpha$-synuclein constructs. The amount of toxicity induced by each construct generally reflects the tendency to induce aggregation. These data suggest that $\alpha$-synuclein can be harmful to neurons under conditions that induce its aggregation.

Recent studies on transgenic animals also suggest that aggregation of $\alpha$-synuclein is harmful to neurons. Masliah et al. (2000) noted dopaminergic dysfunction in transgenic mice expressing wild-type human $\alpha$-synuclein. Even stronger effects were observed in Drosophila overexpressing $\alpha$-synuclein. Feany and Bender (2000) observed dopaminergic dysfunction and dopaminergic neuronal death associated with development of $\alpha$-synuclein aggregates. Thus, increasing evidence suggests that neurons with dopamine develop $\alpha$-synuclein aggregates and degenerate as these aggregates develop.

The potential significance of these data is clear. Although the deposits we report here are not Lewy bodies, it is remarkable that they resemble these structures in many of their apparent constituents and are more prone to form in cells bearing pathogenic mutations. This suggests that they may be imperfect markers of the same processes that lead to Lewy bodies in vivo. The data we present here link familial mutations in $\alpha$-synuclein with iron and aggregation and suggest that the pathogenic process in PD involves the pushing of $\alpha$-synuclein protein across a threshold into cellular aggregates, which are, directly or indirectly, toxic to the cells that contain them. Pathogenic $\alpha$-synuclein mutations appear to lower that threshold in vitro and, as we show here, $\alpha$-synuclein overexpression and oxidative stress can also both push transfected cells over this threshold. From a therapeutic standpoint, these data suggest that antioxidants and agents that lead to reduction of $\alpha$-synuclein expression are legitimate targets for therapy and that other causes of PD, whether genetic or environmental, will directly interact with $\alpha$-synuclein metabolism.

\section{REFERENCES}

Behl C, Davis J, Lesley R, Schubert D (1994) Hydrogen peroxide mediates amyloid $\beta$ protein toxicity. Cell 77:817-827.

Castellani R, Siedlak S, Perry G, Smith M (2000) Sequestration of iron by Lewy bodies in Parkinson's disease. Acta Neuropathologica, in press.

Chiueh C, Miyake H, Peng M (1993) Role of dopamine autoxidation, hydroxyl radical generation, and calcium overload in underlying mechanisms involved in MPTP-induced parkinsonism. Adv Neurol 60:251-258. Conway K, Harper J, Lansbury P (1998) Accelerated in vitro fibril forma- tion by a mutant alpha-synuclein linked to early-onset Parkinson disease. Nat Med 4:1318-1320.

Conway KA, Lee SJ, Rochet JC, Ding TT, Williamson RE, Lansbury Jr PT (2000) Acceleration of oligomerization, not fibrillization, is a shared property of both alpha-synuclein mutations linked to early-onset Parkinson's disease: implications for pathogenesis and therapy. Proc Natl Acad Sci USA 97:571-576.

Dickson D, Lin W-L, Liu W, Yen S (1999) Multiple system atrophy: a sporadic synucleinopathy. Brain Pathol 9:721-732.

Feany MB, Bender WW (2000) A Drosophila model of Parkinson's disease. Nature 404:394-398.

Giasson B, Uryu K, Trojanowski J, Lee V (1999) Mutant and wild type human $\alpha$-synucleins assemble into elongated filaments with distinct morphologies in vitro. J Biol Chem 274:7619-7622.

Gibb W, Lees A (1988) The relevance of the Lewy body to the pathogenesis of idiopathic Parkinson's disease. J Neurol Neurosurg Psychiatry 51:745-752.

Goedert M, Spillantini M, Davies S (1999) Filamentous nerve cell inclusions in neurodegenerative diseases. Curr Opin Neurobiol 8:619-632.

Hashimoto M, Hsu L, Sisk A, Xia Y, Takeda A, Sundsmo M, Masliah E (1998) Human recombinant NACP/ $\alpha$-synuclein is aggregated and fibrillated in vitro: relevance for Lewy body disease. Brain Res 799:301-306.

Hashimoto M, Hsu LJ, Xia Y, Takeda A, Sisk A, Sundsmo M, Masliah E (1999) Oxidative stress induces amyloid-like aggregate formation of NACP $/ \alpha$-synuclein in vitro. NeuroReport 10:717-721.

Jenner P, Olanow C (1998) Understanding cell death in Parkinson's disease. Ann Neurol 44:S72-S84.

Koga H, Kondo A, Kimura T, Takamatsu J (1998) Familial multiple system degeneration associated with iron deposition: determination of subcellular localization of elementary iron by energy-dispersive X-ray analysis. Clin Neuropathol 17:35-40.

Leroy E, Boyer R, Auburger G, Leube B, Ulm G, Mezey E, Harta G, Brownstein M, Jonnalagada S, Chernova T, Dehejia A, Lavedan C, Gasser T, Steinbach P, Wilkinson K, Polymeropoulos M (1998) The ubiquitin pathway in Parkinson's disease. Nature 395:451-452.

Markopoulou K, Wszolek Z, Pfeiffer R, Chase B (1999) Reduced expression of the G209A $\alpha$-synuclein allele in familial parkinsonism. Ann Neurol 46:374-381.

Martin WR, Roberts TE, Ye FQ, Allen PS (1998) Increased basal ganglia iron in striatonigral degeneration: in vivo estimation with magnetic resonance. Can J Neurol Sci 25:44-47.

Masliah E, Rockenstein E, Veinbergs I, Mallory M, Hashimoto M, Takeda A, Sagara Y, Sisk A, Mucke L (2000) Dopaminergic loss and inclusion body formation in alpha-synuclein mice: implications for neurodegenerative disorders. Science 287:1265-1269.

Ostrerova N, Petrucelli L, Farrer M, Mehta N, Alexander P, Choi P, Palacino J, Hardy J, Wolozin B (1999) $\alpha$-Synuclein shares physical and functional homology with 14-3-3 proteins. J Neurosci 19:5782-5791.

Paik S, Shin H, Lee J, Chang C, Kim J (1999) Copper(II)-induced selfoligomerization of $\alpha$-synuclein. Biochem J 340:821-828.

Papadimitriou A, Veletza V, Hadjigeorgiou G, Patrikiou A, Hirano M, Anastasopoulos I (1999) Mutated alpha-synuclein gene in two Greek kindreds with familial PD: incomplete penetrance? Neurology 52:651-654.

Polymeropoulos M, Higgins J, Golbe L, Johnson W, Ide S, Di Iorio G, Sanges G, Stenroos E, Pho L, Schaffer A, Lazzarini A, Nussbaum R, Duvoisin R (1997) Mapping of a gene for Parkinson's disease to chromosome 4q21-q23. Science 276:1197-1199.

Saudou F, Finkbeiner S, Devys D, Greenberg M (1998) Huntingtin acts in the nucleus to induce apoptosis but death does not correlate with formation of intranuclear inclusions. Cell 95:55-66.

Serpell LC, Berriman J, Jakes R, Goedert M, Crowther RA (2000) Fiber diffraction of synthetic alpha-synuclein filaments shows amyloid-like cross-beta conformation. Proc Natl Acad Sci USA 97:4897-4902.

Spillantini MG, Schmidt ML, Lee VM, Trojanowski JQ, Jakes R, Goedert M (1997) $\alpha$-Synuclein in Lewy bodies. Nature 388:839-840.

Spillantini MG, Crowther RA, Jakes R, Hasegawa M, Goedert M (1998) $\alpha$-Synuclein in filamentous inclusions of Lewy bodies from Parkinson's disease and dementia with lewy bodies. Proc Natl Acad Sci USA 95:6469-6473.

Tanner C, Ottman R, Goldman S, Ellenberg J, Chan P, Mayeux R, Langston J (1999) Parkinson disease in twins: an etiologic study. JAMA 281:341-346.

Wolozin B, Behl C (2000) Mechanisms of neurodegenerative disorders. I. Protein aggregates. Arch Neurol 57:793-796. 